\title{
Sulfamethoxazole dosage in monitoring the treatment of paracoccidioidomycosis patients treated with cotrimoxazole.
}

\author{
CAVALCANTE RS'1, PEREIRA BS ${ }^{1}$, MAÇON C', MENDES RP1. \\ 1 Universidade Estadual Paulista (UNESP), Faculdade de Medicina de Botucatu, Botucatu, São Paulo - Brazil; \\ E-mail: mip.ricardo@gmail.com
}

\section{INTRODUCTION}

Paracoccidioidomycosis (PCM) is one of the major systemic mycoses in Brazil, caused by fungi of the genus Paracoccidioides.

Trimethoprim-sulfamethoxazole, also called cotrimoxazole (CMX), one of the drugs most used in the PCM treatment, can be monitored by the serum dosage of the sulfamethoxazole (SMX).

\section{OBJECTIVES}

The objective of this study was to evaluate the impact of serum levels of SMX during treatment in PCM patients treated with $\mathrm{CMX}$ on clinical and serological response.

\section{PATIENTS AND METHODS}

- Thirty-six patients with a confirmed PCM diagnosis

- Patients underwent monthly SMX dosing until clinical cure and every three months until serologic cure

- SMX adequate serum levels: $80 \%$ or more of the measurements reached desired therapeutic values $(70 \mathrm{mg} / \mathrm{mL}$ until clinical cure and $50 \mathrm{mg} / \mathrm{mL}$ until serological cure).

- Statistical analysis: to evaluated the variables as a function of time was performed Kaplan-Meier curves and Cox regression. The significance level was established as $p<0.05$.

\section{RESULTS}

Table 1. Multivariate analysis performed to identify predictors of the time to clinical and serologic cure in 36 paracoccidoidomycosis patients.

\begin{tabular}{|c|c|c|}
\hline & Hazard ratio $(95 \% \mathrm{Cl})$ & $p$ value \\
\hline \multicolumn{3}{|l|}{ Clinical cure } \\
\hline \multicolumn{3}{|l|}{ Clinical form } \\
\hline \multicolumn{3}{|l|}{ Moderate chronic (reference) } \\
\hline Severe chronic & $0,46(0,09-2,24)$ & 0,33 \\
\hline Severe acute & $0,74(0,23-2,36)$ & 0,61 \\
\hline Initial DID & $0,89(0,70-1,15)$ & 0,40 \\
\hline Sulfa serum levels $\geq 70 \mathrm{mg} / \mathrm{mL}$ & $3,70(1,37-9,96)$ & 0,01 \\
\hline \multicolumn{3}{|l|}{ Serologial cure } \\
\hline \multicolumn{3}{|l|}{ Clinical form } \\
\hline Moderate chronic (reference) & $\ldots$ & \\
\hline Severe chronic & $1,61(0,32-8,08)$ & 0,55 \\
\hline Severe acute & $1,03(0,35-3,02)$ & 0,95 \\
\hline Initial DID & $0,74(0,56-0,97)$ & 0,03 \\
\hline Time to clinical cure & $0,99(0,99-1,00)$ & 0,30 \\
\hline Sulfa serum levels $\geq 50 \mathrm{mg} / \mathrm{mL}$ & $2,37(1,04-5,40)$ & 0,04 \\
\hline
\end{tabular}

IC $95 \%=$ confidence interval; DID = immunodiffusion in agar gel specific for Paracoccidioides brasiliensis

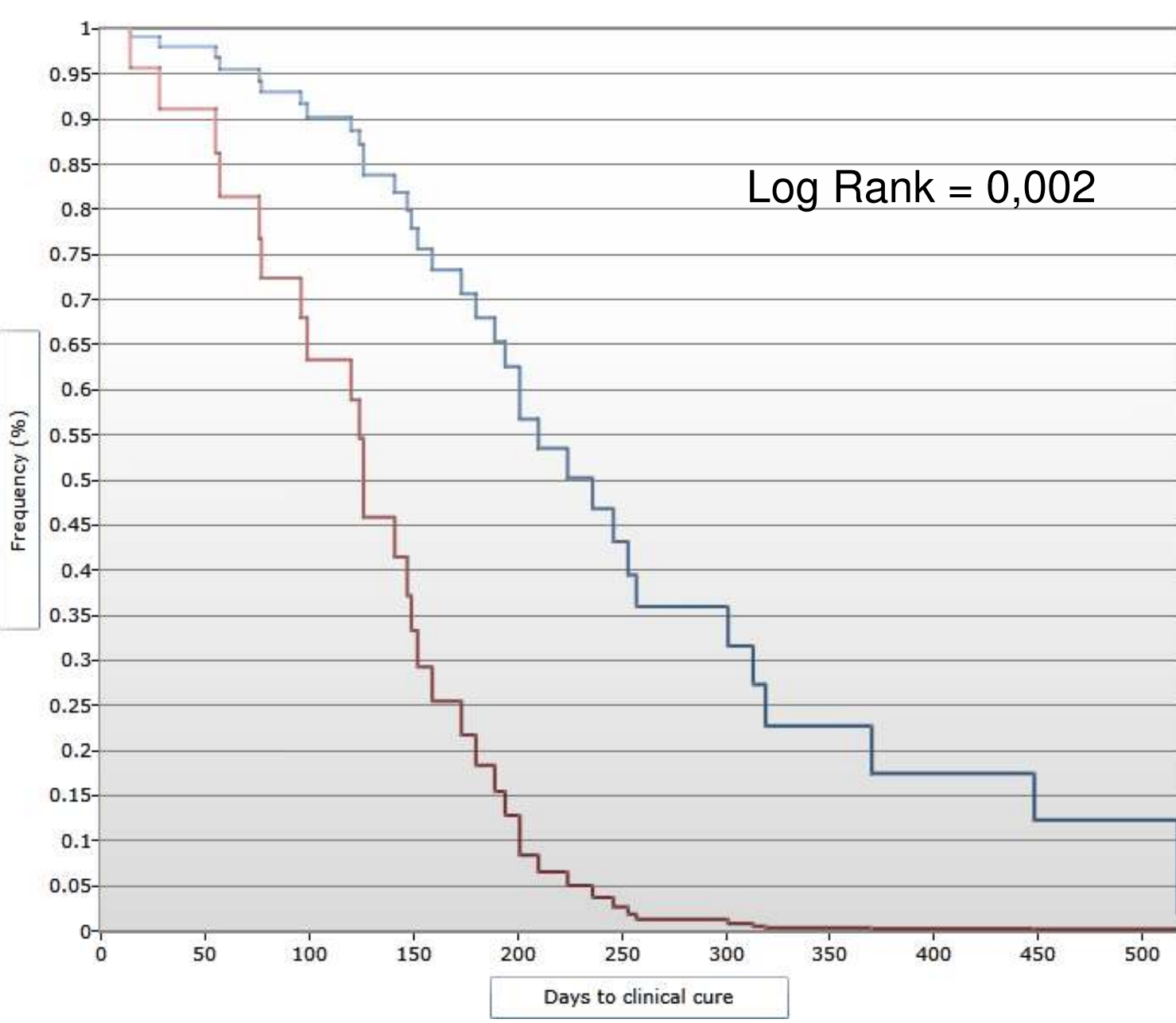

Figure 1. Kaplan-Meier curve to evaluate the time to clinical cure in 36 paracoccidoidomycosis patients as to sulfamethoxazole serum levels. $\mathrm{SMXc70}=0$ indicates individuals with less than $80 \%$ of the measurements above $70 \mathrm{mg} / \mathrm{mL}$ and $\mathrm{SMXc70}=1$ indicates individuals with more than $80 \%$ of the measurements above $70 \mathrm{mg} / \mathrm{mL}$.

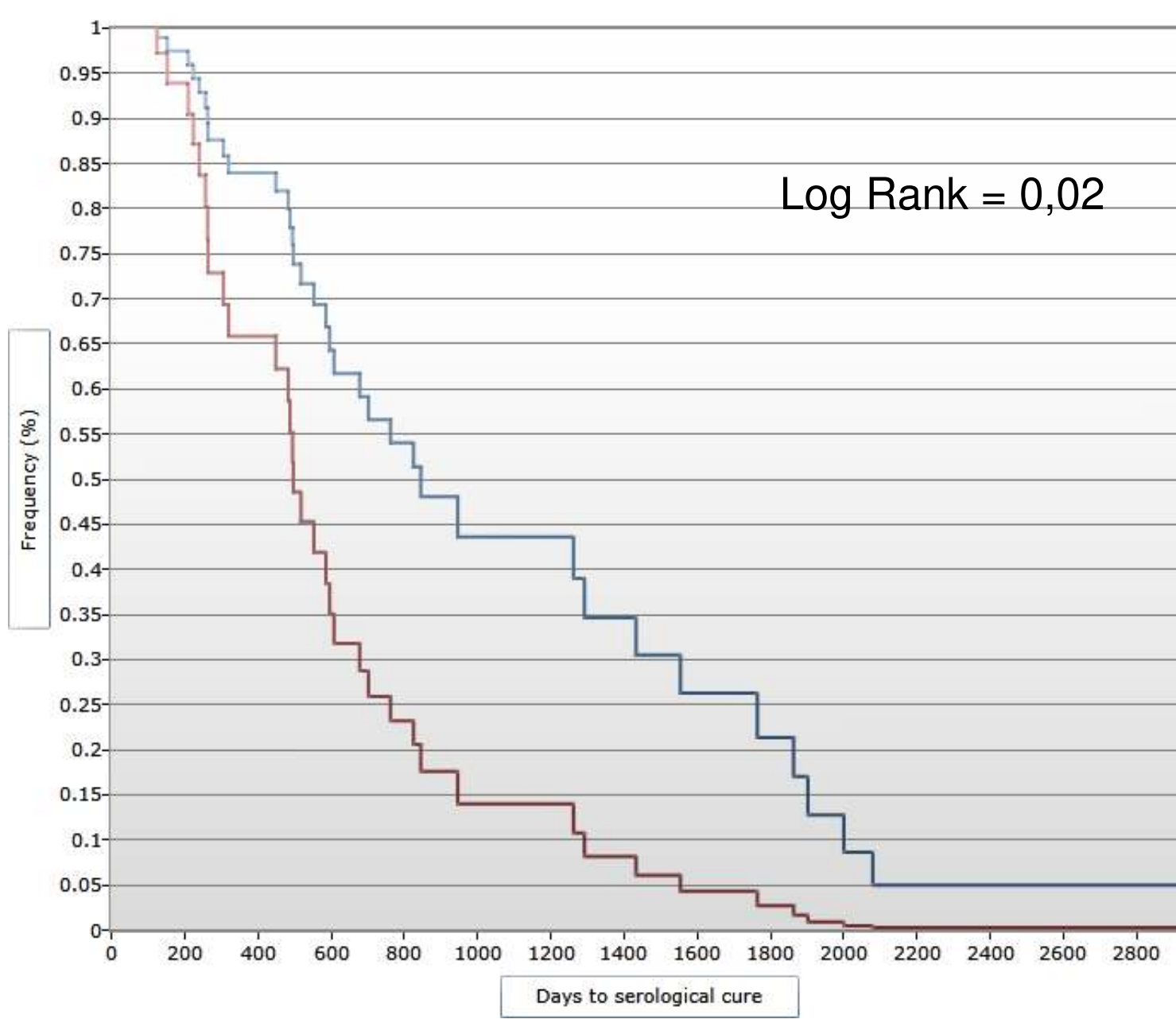

Figure 2. Kaplan-Meier curve to evaluate the time to serological cure in 36 paracoccidoidomycosis patients as to sulfamethoxazole serum levels. SMXs $50=0$ indicates individuals with less than $80 \%$ of the measurements above $50 \mathrm{mg} / \mathrm{mL}$ and $\mathrm{SMXs} 50=1$ indicates individuals with more than $80 \%$ of the measurements above $50 \mathrm{mg} / \mathrm{mL}$.

\section{CONGLUSION}

These findings demonstrate the great importance of serum monitoring of SMX levels during the PCM treatment with $\mathrm{CMX}$ for earlier clinical and serologic cure. 